\title{
Yerel Yönetimlerin Çocuğa Yönelik Örgütlenmesi ve Politikaları: Seçilmiş Ülkeler Üzerinden Bir Değerlendirme
}

\author{
$\ddot{O} z$
}

Levent MEMIŞ*

Çocuklar, çocuk olmasından dolayı özel olarak birtakım haklara sahiptir. Bu haklar farklı belgelerde ifade edilmekle birlikte, çocuk hakları konusunda en temel belge 20 Kasım 1989 tarihinde benimsenerek 14 Eylül 1990 tarihinde yürürlük kazanan "Çocuk Haklarına Dair Birleşmiş Milletler Sözleşmesi”dir. Çocuğun sağliklı bir birey olarak gelişmesine odaklanan bu Sözleşme'de; ayrımcılık yasağı, yaşama ve gelişme, yararına öncelik tanıma, görüşleri dikkate alma ve katılım sağlama ilkeleri benimsenmektedir. Benimsenen ilkeler çerçevesinde toplumun hassas bir tarafını oluşturan çocukların olumsuzluklarla karşılaşmaması ve yaşam kalitesinin sağlanması adına, kamu yönetimi içinde ayrı örgütlenmelere ve politikalara ihtiyaç duyulmaktadır. Yukarıda ifade edilenler kapsamında bu çalışmada çocuklarla ilgili göstergelerde öne çıkan ülkelerde (Norveç, İsveç, Hollanda, İzlanda, Belçika ve Portekiz) nasıl bir örgütsel yapının geçerli olduğu ve hangi tür politikaların öne çıktığı inceleme konusu yapılmaktadır. Gerçekleştirilen incelemede çocuğa yönelik örgütlenmede, ülkelerin yönetim yap1 ve kültürlerinin etkili olduğu, çocuk istismarını kapsayan çocuk koruma konusunda merkezi yönetimin öne çıktığı tespit edilmektedir. Yerel yönetimlerin ise merkezi yönetimi tamamlayacak şekilde çocuk koruma konusunda bazı görevler üstlenmekle birlikte daha çok eğitim, çocuk refahı ve sosyal hizmetler alanında öne çıktığı anlaşılmaktadır. Ayrıca ilgili ülkelerde çocuklar ağırlıklı olarak sağlık ve sosyal hizmetler sistemi kapsamında ele alınmakla birlikte aile odaklı (katılım ve ilişki kurma esasına dayalı) yaklaşımların da önem kazandığı görülmektedir.

Anahtar Kelimeler: Çocuk, Çocuklara Yönelik Politikalar, Yerel Yönetimler

\section{Organization and Policies of Local Governments for Children: An Evaluation Considering Selected Country Cases}

\begin{abstract}
Children have special rights, due to being children. Although these rights are expressed in various documents, the most basic document on the rights of the child was adopted in 20 November 1989 and came into force in 14 September 1990 as "United Nations Convention on the Rights of the Child". In this Conventions, which focuses on the development of the child as a healthy individual; the principle of non-discrimination, life and development, giving priority to their own benefit, taking into consideration the opinions and proving participation were adopted. Within the framework of the principles adopted, separate organizations and policies are needed within the public administration in order to ensure that children who form a sensitive side of society do not encounter negative issues and their quality of life is ensured.Within the scope of these statements, this study examines how organizational structure is valid in the countries that are prominent in child indicators (Norway, Sweden, the Netherlands, Iceland, Belgium and Portugal) and what kinds of policies stand out. In the examination conducted, it was found that the structures of governments of these countriesand cultures are effective in child-oriented organization, and that centralized management is prominent in child protection, which covers child abuse.Local authorities however undertake some tasks on child protection (such as the child protection committees of municipalities in Iceland and municipal child commissions in Portugal) to complement the central government but are understood to be more prominent in the field of education, child welfare and social services.In addition, it is observed that in the relevant countries, the child is mainly covered by the health and social services system, but also family-oriented (based on participation and relationship building) approaches have gained importance.
\end{abstract}

Keywords: Risk, School Dropout, Individual Factors, Social Factors

Received/Geliş: 02.01.2020

Accepted/Kabul: 04.06.2020

Etik Kurul Başvuru tarihi: 27.02.2020

Etik Kurul Rapor tarihi: 09.04.2020

\footnotetext{
* Dr. Öğr. Üyesi, Giresun Üniversitesi, İİBF, Siyaset Bilimi ve Kamu Yönetimi Bölümü, levent_memis@hotmail.com, levent.memis@giresun.edu.tr, (D/0000-0002-5438-691X

(Makale türü: Araştırma makalesi)
} 


\section{Giriş}

Çocuklar, ayrıca özen gösterilmesi ve politikalar geliştirilmesini gerekli kılan bir tarafı oluşturmaktadır. Dünya genelindeki çocuk sayısı 2.2 milyar olarak bilinmektedir (Humanium, 2019). Türkiye açısından ise, 2018 yılı verilerine göre, nüfusun \%28'ini çocuklar oluşturmaktadır. Türkiye'nin çocuk nüfusunda yıllar itibariyle bir azalma görülmekte, gelecek 40 yıllık zaman diliminde de \%20'lik bir oranla devamlılık göstereceği tahmin edilmektedir [TUİK (İstatistiklerle Çocuk), 2019].

Çocuklara gerekli hassasiyet gösterilmediğinde, bireysel (sağlık ve gelişim açısından) toplumsal, fiziksel/mekânsal, teknolojik (bkz. UNİCEF, 2017) vb. kaynaklı risklere bağlı birçok problemle karşılaşılması kaçınılmaz olmaktadır. Dünya Sağlık Örgütü'nün verilerine göre dünya genelinde 720 milyon çocuk şiddete maruz kalmakta, 40 milyon çocuk istismara uğramakta, 250 milyondan fazla çocuk okula gidememekte, 5-17 yaş arası 218 milyon çocuk çalışmakta, beş yaş alt1 51 milyon çocuk yeterli beslenememektedir (TRT Haber, 2019). Bu bağlamda çocuğun yaşamında; beslenme, bakım, aile içinde uygun ortam, eğitim (biçimsel ve biçimsel olmayan boyutlarıyla), oyun, spor, sanatsal-kültürel faaliyetler, güvenlik, mekân, ilgili kararlara katılım gibi hususlar önemli konuları temsil etmektedir. İfade edilen konuların önemsenmesi ve uygulamada karşılığını bulması adına uluslararası düzeyde çeşitli çabaların gösterildiği bilinmektedir. Çocuklar konusunda uluslararası düzeyde belirleyici olan en temel belge "Çocuk Haklarına Dair Birleşmiş Milletler Sözleşmesi’dir. Sözleşme'de temel düzeyde çocuğa yönelik: ayrımcılık yasağı, yaşama ve gelişme, yararına öncelik tanınması, görüşlerinin dikkate alınması ve katılımın sağlanması ilkelerine yer verilmektedir (Akyüz, 2010).

Uluslararası düzeyde ortaya çıkan gelişmelerin de önemli katkısıyla, özellikle gelişmiş olarak nitelendirilen ülkeler düzeyinde çocukların esenliğini, mutluluğunu, sağlığını, güvenliğini ve mahremiyetini sağlayacak çeşitli politikaların geliştirildiği ve uygulamaya aktarıldığ1 bilinmektedir. Aynı çabanın ekonomik olarak gelişmemiş ülkelerde karşıllğını bulmaması (bkz. UNICEF, 2019), bu ülkelerdeki çocuğa yönelik durumların iyileştirilmesini, hem örgütsel hem de politikaların hayata geçirilmesi açısından ayrıca önemli kılmaktadır.

Diğer taraftan ülkelerin yönetim yapıları ve kültürleri, çocuklarla ilgili politikalarda da belirleyici olmaktadır. Yerel yönetim kültürü ağırlık kazanan ülkelerde çocuklara yönelik politikalar yerel yönetimlere ve özellikle de belediyelere bırakılırken; merkeziyetçilik kültürü ağırlık kazanan ülkelerde ise daha çok bakanlıklar düzeyinde, taşraya uzanan örgütsel yapısıyla yerine getirilmeye çalışıldığı anlaşılmaktadır. Özellikle çocuk istismarını kapsayan çocuk koruma konusunda merkezi örgütlenme öne çıkmaktadır. Yerel yönetimler ise merkezi yönetimi tamamlayacak şekilde çocuk koruma konusunda bazı görevler üstlenmekle birlikte daha çok eğitim, çocuk refahı, sosyal hizmetler alanında öne çıkmaktadır. Ayrıca çocuklarla ilgili çeşitli 
meselelerin bazı ülkelerde ağırlıklı olarak sosyal hizmet alanına, bazı ülkelerde de sağlık sistemine dahil edildiği anlaşılmaktadır (Price-Robertson, Bromfield ve Lamont, 2014). Diğer taraftan çocuk refahı konusunda öne çıkan ülkelerde daha çok aile odaklı (katılım ve ilişki kurma esasına dayalı) çocuğun ele alındığı da bilinmektedir (Akt. Freymond, 2007).

$\mathrm{Bu}$ çalışmada temelde çocuklarla ilgili politikalarda öne çıkan, yönetsel açıdan birbirinden farklılık gösteren bazı ülkelerde (Norveç, İsveç, Hollanda, İzlanda, Belçika ve Portekiz) (bkz. SavetheChildren, Global Childhood Report* 2019) nasıl bir örgütsel yapının geçerli olduğu ve hangi tür politikaların öne çıktığı inceleme konusu yapılmaktadır. Ülke örneklerinin sayısını artırmak mümkündür. Çalışmanın sınıllılı̆̆ dikkate alınarak yer verilen ülkelerin incelenmesi tercih edilmiştir. Çalışmanın sonunda elde edilen bilgiler çerçevesinde Türkiye'ye yönelik birtakım öneriler getirilmektedir.

\section{Norveç'de Çocuğa Yönelik Örgütlenme ve Öne Çıkan Politikalar}

Norveç, üniter devlet yapısıyla, başkanlık sistemine dayalı anayasal monarşiyle yönetilmektedir (UNPAN, 2006: 2). Ülkenin yönetim yapısı üç düzeyde; merkez, bölge ve yerel örgütlenmelerden oluşmaktadır (Akt. Dede, 2011). Yerelde, merkezin bir uzantısı olarak il yönetim birimi bulunmakta, fakat il konseyleri (19) ve belediyeler (434) öne çıkmaktadır (Akarçay, 2017: 362). Yerelde hizmetlerin yerine getirilmesi açısından belediyelere önemli yetki ve sorumluluk verilmiştir. Fakat belediyelerin, hizmetler arasından en fazla eğitim için bütçelerini kullandıkları anlaşılmaktadır (Norwegian Ministry of Local Government and Modernisation, 2014).

Norveç'in demografik yapısı incelendiğinde $0-15$ yaş aralığında çocuklar, nüfusun \% 18,9'una karş1ık gelmekte, bu noktada yaşa göre yapılan nüfus sinıflandırmasına göre üçüncü sırada yer almaktadır ("Key figures for the population”, 2019). Gerçekleştirilen çeşitli endeksler (Save the Children, Kidsrights Index vb.) incelendiğinde de Norveç'in çocuklar için dünyada en iyi yerlerden biri olduğu görülmektedir.

Norveç'de çocuklarla ilişkili farklı durumlara yönelik politikaları kapsayan, güncelliğini koruyan en temel düzenleme 1992 yılında çıkarılan Çocuk Refahı Yasası'dır (Skivenes, 2011). Adı geçen Yasa kapsamında çocuk refahı sistemi şu dört ilkeye dayandırılmaktadır: 1. En iyi ilgi (beşt interest), 2. Çevreyle ilişkilerinde dengelilik (stability principle), 3. Biyolojik prensip (biological principle), 4. En az müdahale (leastintrusive form of intervention) (Skivenes, 2011). Ve son 30 yılda gerçekleştirilmeye çalışılan çocuk politikalarının; koruma, önleme, firsat eşitliği ve refaha erişim aşamaları üzerinden gerçekleştiği vurgulanmaktadır (Skivenes, 2011). Çocuk

\footnotetext{
* Save the Children, 100 y1l önce Londra'da oluşumu gerçekleşen, 117 ülkede 25.000 gönüllüsüyle çocuklara yönelik faaliyetlerini yürüten bir STK'dır. Üçüncü defa düzenlendiği anlaşılan indeks, 176 ülke kapsamında, sağlık, yetersiz beslenme, eğitimden dışlanma, çocuk işçiliği, çocuk evliliği, erken hamilelik, şiddete bağlı ölümler gibi kriterler üzerinden gerçekleştirilmiştir. İlgili STK'nın kurumsallaşmış yapısı, belirlenen kriterlerin ve ülke örnekleminin kapsayıcılığı, bu araştırmada referans olarak alınmasının dayanaklarını oluşturmaktadır (https://www.savethechildren.net/, 14. 05. 2020; Global Childhood Report, 2019).
} 
refahı hizmetleri, merkezi yönetim ile yerel yönetimlerin yetki ve sorumluluğu altında yerine getirilmektedir. Bu noktada faaliyetler, ulusal düzeyde Çocuk ve Aile Bakanlığı çatısı altında oluşturulan bir direktörlük (Diretorate for Children, Youth and Family Affairs) ile yürütülmektedir. Yine çocuklarla ilgili konularda, il düzeyinde valilere denetleme ve danışmanlık görevleri verildiği anlaşılmaktadır. Ayrıca il düzeyinde (12 adet) çocukların korunmasına yönelik kararı vermekle yetkilendirilen İl Sosyal Refah Kurulu (County Social Welfare Board) adiyla bir birim faaliyet göstermektedir (Güngör, t.y.).

Yerelde ise çocuklara yönelik hizmetlerin yerine getirilmesi adına belediyelere bir takım görev ve sorumluluklar verildiği anlaşılmaktadır. Bu bağlamda belediyelerin esnek bir sisteme sahip olduğu vurgusu yapılmaktadır (Kojan, 2011). Ayrıca belediyelerin büyüklüğüne göre çocuklara yönelik örgütlenmesi de değişkenlik göstermektedir (Skivenes, 2011). Belediyeler çocuk refahı hizmetleri kapsamında; çocukların durumunu araştırmak, değerlendirmek, rehberlik etmek ile hizmetlerin en iyi şekilde yerine getirilmesinden sorumlu tutulmaktadır (Kojan, 2011). Ülkede bir yaşını dolduran çocukların, yaşadıkları yerlerdeki belediyelerin açmış olduğu kreşe gitme hakkı bulunmaktadır. Bu bağlamda ülkede bulunan 1-5 yaş aralığındaki çocukların \%90’1 kreşe gitmektedir. Belediyeler, ülkede bulunan anaokulların yaklaşık \%50'sine sahiptir. Diğer \%50'lik kısmını ise özel sektör yürütmektedir (Pettersen ve Monsen, t.y.).

\section{İsveç'de Çocuğa Yönelik Örgütlenme ve Öne Çıkan Politikalar}

İsveç, parlamenter monarşiyle yönetilen üniter bir devlettir. Ülkenin yönetim yapısı, merkezi ve yerel birimlerden oluşmaktadır. Ülke, bölgesel örgütlenme bağlamında 21 il kademesine ayrılmış olup, her ilde üyeleri seçimle belirlenen bir il meclisi bulunmaktadır. Diğer taraftan her ilde belediyeler yer almaktadır. Toplamda 300'e yakın belediye bulunmaktadır. Belediyelerin alt birimlerini ise mahalleler oluşturmaktadır. İfade edilenler bağlamında vurgulanan temel husus ülke yönetiminin, büyük oranda yerel yönetim kültürü ve yapısına dayanmasıdır ("Vikipedi-İsveç", 2019; Regeringskanliet-Finansdepartementet, 2005).

İsveç’in de içinde yer aldığı İskandinav ülkeleri, “İskandinav Refah Modeli” olarak da nitelendirilen sosyal politika uygulamalarıyla öne çıkmaktadır (Nososco, 2017). Sosyal politika uygulamalarının hayata geçirilmesinde, yerel yönetimlere önemli roller verilmektedir (Nordfeldt ve Larsson, 2011). Bu noktada farklı konularda birçok hizmet belediyeler tarafından yerine getirildiği gibi, aileleri ve çocukları da kapsayan sosyal hizmetler alanında da belediyelerin yetkili ve sorumlu kılındığı anlaşılmaktadır (Regeringskanliet-Finansdepartementet, 2005; Nososco, 2017). Bu bağlamda aile desteği politikaları bağlamında belediyeler tarafından, çocuk bakımı hususunda şu hizmetler yerine getirilmektedir: okul öncesi eğitimi, aile gündüz bakım evleri, anaokuluna bir alternatif olarak açık kreş (open preschool), serbest zaman merkezi (leisure-time 
centre) ve açık serbest zaman faaliyetleri (open leisure-time activities) (Akt. Nordfeldt ve Larsson, 2011; bkz.: Nososco, 2017).

İskandinav ülkelerinin çocuk istismarıyla mücadele kapsamında ortaya çıkan Barnahus uygulaması, İsveç’te de karşılık bulmaktadır. İskandinav ülkelerinde bazı farklılıklarla 2000'li yılların ortalarından itibaren ortaya çıkan bu uygulama bir model oluşturarak, diğer ülkelerde de uygulanmaya başlanmıştır (Johansson vd., 2017). İskandinav ülkelerinde genel boyutta ülkedeki refah uygulamaları bağlamında çocuk refahının bir parçası olarak uygulanan Barnahus modelinin temel özellikleri; disiplinler arası iş birliği, açık kapı prensibi, ikincil mağduriyetten kaçınma, ifadeler için güvenli ve uzmanlar için tarafsız bir yer olarak belirtilmektedir (Johansson vd., 2017).

Ayrıca vurgulamak gerekir ki, İskandinav ülkelerinin çocuk refahı sistemi, "aile odaklı hizmet" (family service-oriented) yaklaşımına dayanmaktadır (Johansson vd., 2017). Barnahus uygulaması ise daha çok çocuk koruma odaklı (child-focused-orientedsystems) bir sisteme karş1l1k gelmektedir. Bu nedenle çocuk dostu ortamlar ve çocuk katılımı, modelin merkezi unsurlarındandır (Johansson vd., 2017).

\section{Hollanda'da Çocuğa Yönelik Örgütlenme ve Öne Çıkan Politikalar}

Hollanda, bazı kendine özgü özellikleriyle anayasal monarşiye dayalı üniter bir devlettir. Ülkenin yönetim yapıs1; merkez, eyalet (12), belediye (380) ve bölgesel su birimleri olmak üzere dört temel yapıdan oluşmaktadır (VNG, 2018). Fakat ülkenin tarihsel geçmişi, yönetim yapısının adem-i merkeziyetçilik üzerine kurulu olduğunu yansıtmaktadır (Akt. Kargın, 2013). Daha çok icrai bir birim olarak konumlandırılan belediyeler; planlama, konut, çevre koruma, yolların bakım ve onarımı, sosyal hizmetler gibi çeşitli faaliyetleri yerine getirmektedir (Kargın, 2013).

Hollanda, 0-25 yaş aralığında bulunan kişileri çocuk ve genç olarak nitelendirmektedir (Darwish, van Gaal ve Nuyens, 2012). Ülkenin, çocuk ve gençlere yönelik sosyal hizmetler konusunda uzun bir deneyime sahip olduğu anlaşılmaktadır (bkz. Lopez vd., 2019). Bu bağlamda ülkenin geleneksel yönetim yapısı içinde çocuk ve gençlere yönelik hizmetler farklı bakanlıklar kapsamında gerçekleştirilmektedir. Zaman içinde karşılaşılan olumsuzluklar yeni örgütsel düzenlemeleri gerekli kılmıştır. Bu noktada her yıl 100.000'den fazla çocuğun istismara (childabuse) uğramas1, merkezi yönetimi "Evde Çocuk Güvenliği” (Children Safe at Home) adıyla hazırlanan eylem planı (2008-2010) üzerinden harekete geçirmiştir (Baat vd., 2011). Diğer taraftan 2010 yılında ülkede seçimlerin yenilenmesiyle; önleme, algılama, durdurma ve çocuk istismarı zararlarının en aza indirilmesi, çok aktörlü iş birliğinin teşvik edilmesi, korunmaya özel önem verilmesi, çocukların fiziksel güvenliği gibi konuları kapsayan yeni bir eylem planı (20122016) hazırlanmıştır (Baat vd., 2011: 9). Ayrıca bu eylemleri daha etkin hale getirecek, mevcut 
sistemden kaynaklı işlevsizlikleri iyileştirmek amacıyla yeni örgütsel düzenlemelere de gidilmiştir (ESN, 2014; Baat vd., 2011).

İfade edilenler kapsamında, 2015 yılında gerçekleştirilen bazı yeni düzenlemelerle çocuk ve gençlerin de dahil olduğu sosyal hizmet alanında belediyelere daha fazla yetki ve sorumluluk aktarıldığı anlaşılmaktadır (Hilverdink, Daamen ve Vink, 2015; Vermeulen, 2015). Bu kapsamda çocuk ve gençlere yönelik şu düzenlemelere gidilmiştir: Çocuk ve Gençlik Yasası (Child and Youth Act, 2015), Sosyal Destek Yasası (Social Support Act, 2015), Kat1lım Yasası (Participation Act, 2015) ve Uygun Eğitim Yasası (Act on Appropriate Education, 2014). Bu düzenlemelerle merkezi düzeyde farklı bakanlıklardaki yetki ve sorumlulukların önemli kısmı belediyeler üzerinden yerele aktarılmış, bu konuda belediyeler temel aktör haline getirilmeye çalışılmıştır. Ayrıca düzenlemeler arasında Çocuk ve Gençlik Yasası'nın öne çıkan bir rolünün bulunduğu anlaşılmaktadır. Yasanın temel amacı, özel bakıma muhtaç çocuk sayısını azaltmak, önleyici ve erken müdahale desteğini artırmak ve çocukların doğrudan ortamlarında sosyal ilişkilerini teşvik etmek şeklinde öne çıkarılmaktadır (Netherland Youth Institü, 2019).

Belediyelerin yetki ve sorumluluğu altında, hizmetlerin entegrasyonu ve daha iyi koordinasyonu, önleme, koruma süreci içinde sosyal ağların ve ailenin rolü üzerine durulabilecektir. Benimsenen temel ilke; "bir aile, bir plan ve bir koordinatör" şeklindedir. (ESN, 2014). Anlaşılmaktadır ki, çocuklara yönelik hizmetler, yerinde ve ihtiyaca özel sunulmaya çalışılmaktadır. Bu sayede çocuklar, gençler ve aileler için daha tutarlı, daha etkili, daha şeffaf ve daha ucuz hizmetlerin ortaya çıkması beklenmektedir (Hilverdink, Daamen ve Vink, 2015).

İfade edilenler çerçevesinde genel olarak ele alındığında da Hollanda, gençlik koruma ve refah sistemi kapsamında üç ana hizmeti yerine getirmektedir. Gençlik çalışmaları, çocuk bakımı ve okul faaliyetlerinin dahil olduğu evrensel hizmetler; çocuk sağlı bakımı, genel sosyal çalışmalar ve aile desteğinin yer aldığı önleyici hizmetler ve gençlerin bakımı, gençlerin akı1 sağlı̆̆ı hizmetleri ve çocuk koruma hizmetlerinden oluşan özelleştirilmiş hizmetlerdir (Netherlands Youth Institute, 2019; bkz. Baat vd., 2011).

Diğer taraftan özellikle çocuk istismarıla mücadele etmek amacıyla Belçika'da olduğu gibi Hollanda'da farklı işlevleriyle çocuk izleme merkezlerinden (Confidential Doctor Centres/Office) yararlanıldığı anlaşılmaktadır (Sanders, 2018). İlki 1972 yılında kurulduğu anlaşılan merkez, Çocuk Bakım ve Koruma Kurulu'na bir alternatif olarak kurulduğu anlaşılmaktadır. Merkez, çocuk istismarı bağlamında gelen başvurular üzerine harekete geçmekte ve bir plan dahilinde ailelerle çalışmalarını yürütmektedir (Akt. Freymond, 2007).

\section{İzlanda'da Çocuğa Yönelik Örgütlenme ve Öne Çıkan Politikalar}

İzlanda, 358. 780 nüfusa sahip, anayasal cumhuriyet ile yönetilen bir ada ülkesidir ("Vikipedi-İzlanda", 2019). Yönetim yapısı, merkezi ve yerel yönetimlerden oluşmaktadır. Yı1lar 
içinde sayısal bir azalma söz konusu olsa da belediyeler, yerel yönetimler arasında öne çıkan temel birimdir (Broz ve Wienen, 2017). Belediyelerin, halk sağlığının gözetilmesi ve ticari yaşamın sağlanması adına idari; çeşit gruplara sosyal hizmetlerin sağlanması amacıyla refah; altyap1, yangın gibi hizmetlerin sağlanması amaciyla teknik görevlerinin bulunduğu belirtilmektedir (Sverrisson ve Hannesson, 2014).

Ülkede çocuklara yönelik en temel düzenleme 2002 yılında yayınlanan "Çocuk Koruma Yasası (Child Protection Act)"dır. Çocukların da yer aldığı sosyal hizmetler Refah Bakanlığı yetki ve sorumluluğu altında yürütülürken, 2019 yılında yapılan yeni bakanlık düzenlemesiyle Sosyal İşler Bakanlığı çatısı altında yürütülmeye başlanmıştır. Bu düzenlemeyle öncesinde faaliyet gösteren Çocuk Koruma Birimi (Government Agency for Child Protection)'nin, yeni oluşturulan Bakanlığın bir birimine dönüştürüldüğü anlaşılmaktadır. Bu birimin temel rolü, çocuk çalışmalarını koordine etmek ve güçlendirmek şeklinde belirlenmiştir. Bu rolü kapsamında birim; ilgili çocuk koruma komitelerinin çalışmalarını izlemekte, çocuk koruma konusunda araştırma ve geliştirme, eğitim ve öğretim, çocuk koruma komitelerine koruyucu ebeveyn bulma konusunda yardımcı olma gibi farklı desteklerle görevlerini yerine getirmektedir (Government Agency for Child Protection, 2019).

Diğer taraftan yerel yönetimler düzeyinde ise Çocuk Koruma Komitesi'ne yer verilmektedir. Çocuk Koruma Yasası'na göre, her yerel yönetim birimi (belediye), beş üyeden oluşan Çocuk Koruma Komitesi oluşturması gerekmektedir. Komitenin temel fonksiyonu, Çocuk Koruma Yasası'nda belirlenen amaçlara göre ailelere destek olmaktır. Ayrıca ülkede uygulanan zorunlu raporlama sistemi gereği, çocukların refahıyla ilgili olumsuz bir durumla karşılaşıldığında, uzmanlar ve vatandaşlar, ilgili durumu komiteye bildirmeleri gerekmektedir. Genel olarak da izleme, ölçme ve diğer görevler başlığı altında roller verildiği anlaşılmaktadır. Diğer taraftan, Çocuk Koruma Yasası'na göre belediyeler, her seçim sonrası dönemde çocuk koruma politikalarını yansıtan bir eylem planı hazırlaması ve merkezi yönetime bildirmesi gerekmektedir (“Government Agency for Child Protection”, 2019).

Diğer İskandinav ülkelerinde de uygulanan ve İzlanda'da da karşıllı̆ını bulan başka bir uygulama ise "Barnahus" olarak isimlendirilen Çocuk Evleri'dir. İlk uygulaması 1985 yılında ABD'de ortaya çıkan Çocuk Adalet Merkezi'ne dayandırılmaktadır. Avrupa genelinde 50 adet bulunan Barnahus'lar, çocuk istismarına yönelik farklı disiplinlerin ve uzmanların yer aldığı, ulusal çocuk koruma sistemine entegre edilmiş, merkezi yönetime bağlı bir birim olarak yerelde kurulmuştur. Bu haliyle farklı tarafların bir araya geldiği bir iş birliği platformu işlevi görmektedir (Johansson, 2017). Temel işlevinin mağdur olan çocuğun, mahkeme öncesi dinlenmeye hazır hale getirmesi şeklinde olduğu belirtilmektedir. Barnahus uygulamasının, Türkiye'de Çocuk İzleme Merkezleri (ÇİM) ile karşı1lık bulduğu anlaşılmaktadır (Akt. Bilgener ve Çalışkan, 2018). 


\section{Belçika'da Çocuğa Yönelik Örgütlenme ve Öne Çıkan Politikalar}

Belçika'nın sahip olduğu demografik özellikler, yönetim yapısının şekillenmesinde de etkili olmuştur. Bu noktada ülke, tarihsel süreç içinde farklı yönetim modellerini uygulamakla birlikte, mevcut durumda; Valon, Flaman ve Alman nüfuslarını barındıran federal bir devlet modeliyle yönetilmektedir. Ülkenin yönetim yapısı üç farklı düzeyde karşılık bulmaktadır. Bunlar; (1) üst ölçekte federal devlet, toplumlar ve bölgeler, (2) orta düzeyde iller (10 adet) ve (3) alt kademede ise belediyeler (589 adet) yer almaktadır. Yapılan düzenlemelerle belediyelerin sayıları azaltılmış ve güçlendirilmiştir. Belediyeler; eğitim, sağlık, planlama, güvenlik, sosyal, kültürel vb. konularda yerelde hizmet sunan en temel birim olarak konumlandırılmaktadır (Akt. Ürkmez, 2013; Crompton, 2017).

Belçika'da çocukların korunmasına yönelik düzenlemeler 1912 yılına kadar geriye gitmekte ve federal yapılanma öncesinde daha çok merkezi yönetim düzeyinde örgütlenildiği (Adalet Bakanlığı Çocuk Koruma Ofisi, Ulusal Çocuk Ajansı, Aile ve Sağlık Bakanlığı gibi) ifade edilmektedir (Emery, 1958). Ülkede çocuk koruma hizmetleri, sağlık sisteminin bir parçası olarak ele alındığı anlaşılmaktadır. Bu kapsamda çocuk istismarı (childabuse) ve korumasıyla ilgili olarak hastane merkezlerinde oluşturulan, farklı bilim dallarından uzmanların yer aldığ 1 Confidential Doctor Centres/Confidential Centres birimi öne çıkmaktadır (Price-Robertson, Bromfield ve Lamont, 2014: 5; Desair ve Adriaenssens, 2011). İlk örneği 1985 y1lında ortaya çıkan Merkez (Sanders, 2018); kriz müdahalesi, danışmanlık, hastanede konaklama, çocuk ve aile terapisi gibi bazı hizmetleri sunmaktadır. Bu sayede çocukların davranışlarını anlamada ve gelecekte çocuklarına zarar vermemek için ailelere yardımcı olmaya çalışılmaktadır (Akt. PriceRobertson, Bromfield ve Lamont, 2014).

Ülkede çocuk refahı sistemi içinde yer alan aracı birimlerin işlevine vurgu yapılmaktadır (Freymond, 2007). Bu bağlamda özellikle Flaman bölgesinde; arabuluculuk komiteleri, Fransızca konuşulan bölgede de aile ile hizmet sağlayıcı arasındaki anlaşma bozulduğunda devreye giren, eğitim almış ve atanmış kişiler olarak danışmanlar (conseiller) öne çıkmaktadır (Freymond, 2007).

Flaman bölgesinde, 2003 yılında yapılan düzenlemeyle (2006 yılında revize edilmiş) (Act on Municipal, Inter-municipal and Provincial Youth and Youth Work Policy) belediye, belediyeler arası ve yerleşimler arası gerçekleştirilecek politikaların belirlenmesi ve desteklenmesi ve teşvik edilmesine yer verilmektedir. 2008 yılında çocuk ve gençlik haklarının politikalarını hayata geçirmek amacıyla bir düzenlemeye gidilmiştir (Flemish Parliament Act). Bu düzenlemenin kapsamı altında çocuk ve gençlik politikaları 2004 yılından itibaren, ağırlıklı olarak Gençlik Bakanlığı bünyesinde oluşturulan birimler (The Agency for Socio-Cultural Work for Youth and Adultsin the Ministry of Culture) üzerinden yürütüldüğü anlaş1lmaktadır. Bu 
kapsamdaki temel belge Flaman Gençlik Politikaları Planı'dır (Flemish Youth Policy Plan, 20112014). Bu bağlamda politikaların hayata geçirilmesinde gençlik örgütlerinin önemli rol oynadığının altı çizilmektedir (Caluwaerts, 2010; Pudar vd., 2013). Diğer taraftan çocuk istismarı ve ihmaliyle ilgili oluşturulan bir birim (Confidential Centres for Child Abus eand Neglect) de bulunmaktadır (Desair ve Adriaenssens, 2011).

Valon bölgesinde gençlik politikaları, Gençlik ve Gençlik Refahı Bakanlığı (Minister for Youth and Youth Welfare) bünyesinde, Gençlik Hizmetleri (Youth Department) başlığı altında yerine getirilmekte ve sosyo-kültürel politikalarının bir bölümünü oluşturmaktadır ("Definition of Youth”, 2019). Bölgedeki politikaların temel belirleyici belgesi hükümet tarafindan hazırlanan gençlik belgesidir. İlgili politikaların hayata geçirilmesinde yerel derneklerin desteklendiği ifade edilmektedir (Caluwaerts, 2010; Pudar vd., 2013). Çocuk istismarı ve ihmaliyle ilgili de bir birim (Centres SOS-Enfants) faaliyet göstermektedir (Desair ve Adriaenssens, 2011).

Almanca konuşulan bölgede ise, merkezi yönetimin güdümünde, sosyo-kültürel faaliyetler çatısı altında çocuk ve gençlere yönelik politikalar hayata geçirilmeye çalışılmaktadır. Yine bu bölgede de gençlik politikalarının hayata geçirilmesinde gençlik örgütlerinin rolüne vurgu yapilmaktadır (Meys, 2010).

\section{Portekiz'de Çocuğa Yönelik Örgütlenme ve Öne Çıkan Politikalar}

Portekiz, 1976 yılında kabul edilen Anayasasıyla demokratik bir cumhuriyet olarak yönetilmektedir. Ülke sahip olduğu üniter yapısıyla merkezi ve yerel yönetimlerden oluşmaktadır. Yerelde ağırlıklı birimi belediyelerden oluşmaktadır. Belediyeler hem ülkenin geçirdiği tarihsel süreç içindeki rolüyle hem de mevcut durumdaki üstlendiği rolüyle önemli konuma sahiptir. Bu bağlamda ülkede 300'ün üzerinde belediye, bu yerleşim kapsamı içinde de 3. 000'den fazla mahalle (parishes) yer almaktadır (https://tr.wikipedia.org/wiki/Portekiz, 28. 08. 2019; Pereira, 1991; Akt. Silva, 2017).

Portekiz'in nüfusu 10.293.000'dir. Bu nüfusun \% 14'ü, 0-14 yaş grubundan oluşmaktadır (“Wikipedia-Portagol”, 2020). Ülkede, 1998 yılında yapılan yasal düzenlemeyle ulusal düzeyinde Risk Altındaki Çocuk ve Gençleri Koruma Komisyonu [National Commission fort he Protection of Children and Youngsters at Risk (CNPCJR)] oluşturulmuştur. Bu Komisyon'un görevi yine aynı amaçla, 1999 yılında bir yasal (Law on the Protection of Children and Youngsters in Peril) düzenlemeyle, belediyelerin sosyal kalkınma planlarıyla ilişkili olarak yerelde oluşturulan komisyonun [Commissions for the Protection of Children and Youngsters at Risk (CPCJ)] desteklemesini ve denetlemesini yapmaktır. Bu noktada ülkede bulunan hemen hemen her belediyede adı geçen komisyon bulunmaktadır. Yerelde oluşturulan bu komisyonun temel amacı, çocuk istismarı ve ihmalini tespit etmek, raporlamak ve durdurmak şeklinde belirlenmektedir. Diğer taraftan da ilgili komisyonlar, çocukların ve gençlerin sahip olduğu hakları iyileştirmek 
veya güvenlik, sağlık, eğitim gibi konularda eksiklikleri gidermek ve belediye bünyesinde ilgili taraflara yönelik etkinlikler düzenlemektir. Ülkede oluşturulan koruma sistemi ikili bir yapıya sahiptir ve sistemin temeli yerindelik (subsidiarity) ilkesi oluşturmaktadır (Berg, 2012; European Commission, 2015). Ayrica koruma sistemi, durumu toplumsal bir mesele olarak ele almakta ve "profesyonel izleme, minimum müdahale ilkesine" dayandırmaktadır (Magalhaes ve Sottomayor, 2015).

Diğer taraftan belediyelerin farklı yöntemleri kullanarak bazı politikalar ürettiği görülmektedir. $\mathrm{Bu}$ noktada 2015 yılında bazı belediyelerin çocuklu aileler için mülkiyet vergilerinde azaltmaya gittiği, 2016 yılında bazı belediyelerin vergi iadesinde bulunduğu anlaşılmaktadır. Yine bazı belediyelerin yeni doğan bebekler için maddi destekte bulunduğu ve geliştirilen çeşitli çalışmalarla aile bireylerine iş imkânları sağlamaya çalışıldığı anlaşılmaktadır (Almeida, 2018).

Türkiye’nin Yerelde Çocuğa Yönelik Örgütlenme/Politika Durumu ve Ülke

\section{İncelemelerinden Elde Edilecek Çıkarımlar}

Türkiye açısından duruma odaklanıldığında çocuklarla ilgili meselelerin genel düzeyde ağırlıklı olarak merkezi yönetimin sorumluluğu altında yoğunlaştığı görülmektedir (Mamur Iş1kç1, 2019). Eğitim hizmetini Millî Eğitim Bakanlığı yürütmektedir. Diğer taraftan Aile, Çalışma ve Sosyal Hizmetler Bakanlığı'nın bir alt örgütlenmesi olarak oluşturulan Çocuk Hizmetleri Genel Müdürlüğü sorumluluğunda Çocuk Evleri (1.192), Çocuk Evleri Sitesi (111) ve Çocuk Destek Merkezi (63*) bünyesinde çocuğa yönelik hizmetlerin sunulduğu anlaşılmaktadır. Çocuklara yönelik oluşturulan hastanelerle hizmet sunan Sağlık Bakanlığı bünyesinde ise istismara uğrayan çocuklara odaklanan, farklı kurumlar arasında iş birliği ihtiyacının bir sonucu olarak ortaya çıkan ÇìM'ler bulunmaktadır (Bilginer ve Çalışkan, 2018). ÇİM'ler, 2010 yılında kurulmuş olup (Bağ ve Alşen, 2016), Kasım 2019 itibariyle Türkiye genelinde 45 adet bulunmaktadır ${ }^{\dagger}$.

Diğer taraftan ağırlıklı olarak merkezi yönetim öne çıkmakla birlikte, çocuk politikaları konusunda yerel yönetimlere de bazı sorumlulukların verildiği görülmektedir. 5393 sayılı Belediye Kanunu (madde 14, 76 ve 77) ile 5216 sayılı Büyükşehir Belediyesi Kanunu'nda (madde 7) çocukla ilişkili olarak bazı düzenlemelere yer verilmektedir. Ayrıca yine ilgili belediye mevzuatının sağladığı esneklikle bazı belediyelerin (Eskişehir, Antalya, İzmir Büyükşehir Belediyeleri vb.) çocuklara yönelik bir alt örgütlenmeye gittiği de tespit edilmektedir.

$\mathrm{Bu}$ noktada kentin genel olarak biçimlendirilmesinde ve politikaların geliştirilmesinde, çocuğun gözünden bakmak önemli bulunmaktadır. Bu bağlamda özellikle ağırlıklı olarak

\footnotetext{
*Veriler Aralık 2018'e aittir. Detaylar için bkz. https://ailevecalisma.gov.tr/uploads/chgm/uploads/pages/istatistikler/20185c62a51c75b1f.pdf, 25. 12. 2019

${ }^{\dagger}$ Detaylı bilgi için bkz. https://khgmsaglikhizmetleridb.saglik.gov.tr/TR,43119/cocuk-izlem-merkezi-cim-listesi.html, 25.12 .2019$.
} 
İstanbul'da yer alan ilçe belediyelerin çabaları öne çıkmaktadır (bkz. Aka ve Güngör, 2019; "Kent95", 2019; Erginli, 2018). Bu hizmetler arasında kreş ve gündüz bakım evleri dikkat çekmektedir. İstanbul genelinde belediyelerin açtığı, yaklaşık 6.000 çocuğun yararlandığ 93 kreş ve gündüz bakım evinin bulunduğu ifade edilmektedir (Erginli, 2018).

Yerelde geliştirilen çocuk politikalarına katılım açısından önemli bir tarafı da STK'lar oluşturmaktadır. Bu noktada Türkiye genelinde, İstanbul (42), İzmir (20), Ankara (19), Bursa (16), Konya (13) gibi büyükşehirlerde yoğunlaşmakla birlikte, çocukla ilişkili olarak 81 ilde 241 STK'nın varlığı tespit edilmektedir (Karatay, 2019). Bu STK'lardan biri de 1990 yılında kurulan, çocuklara yönelik farklı çabalar gösteren Çocuk Vakfı'dır. Yine İstanbul özelinde bazı STK'ların faaliyetleri dikkat çekmektedir. Bu bağlamda Mekânda Adalet Derneği'nin Bernard van Leer Vakfi ile gerçekleştirdiği iş birliğiyle, 3 yaşındaki bir çocuğun gözünden yani $95 \mathrm{~cm}$ 'den, kenti anlaşılmaya çalışıldığ 1 ve yerel yönetimlerin dikkatlerinin çekilmeye ve uygulamaya aktarılmaya çalışıldığı proje (İstanbu195) önemli bir örnek oluşturmaktadır (Detaylı bilgi için bkz. Kent95, 2018). Bu proje kapsamında diğer aktörlerle gerçekleştirilen iş birlikleriyle bazı ilçelerde oyun parkları özelinde çalışmaların yürütüldüğü görülmektedir (Şehir Hepimizin: “Kente 95 cm'den Bakmak", 2019).

Türkiye'de yerel düzeyde çocukları dikkate alan diğer bir uygulama ise, Çocuk Dostu Kent yaklaşımıdır. İtalya'da gelişen ve daha sonra UNICEF'in desteğiyle dünya çapında yaygınlaştırılmaya çalışılan bir kent yaklaşıma dönüşmüştür. Çocuk dostu kent olmak isteyen belediyeler, çocuk haklarıyla ilintili olarak şu ilkeleri benimsemesi gerekmektedir: ayrımcılık yapmamak, çocuğun yüksek yararını gözetmek, çocuğun yaşama ve gelişme hakkını sağlamak ve çocuk görüşüne saygı duymak (Akt. Çakırer-Özservet, 2016). Çocuk dostu şehir yaklaşımı, bir proje üzerinden 2014-2015 yılları arasında Türkiye'deki 10 belediye üzerinden hayata geçirilmeye çalışılmıştır (bkz. "Çocuk Dostu Şehirler”, 2019). İlgili belediyelerde mevcut durumun tespitinden hareketle çocuk eylem planları hazırlanmıştır. $\mathrm{Bu}$ çabalar artırılarak sürdürüldüğünde kent havası çocukları daha fazla özgür kılabilecektir (Çakırer-Özservet, 2018).

Ayrıca yerelde üniversiteler bünyesinde açılan araştırma ve uygulama merkezleri önem kazanmaktadır. Türkiye genelinde üniversiteler bünyesinde 53 merkezin varlığı bilinmektedir (Uludağ ve Mamur Işıkçı, 2019).

Gerçekleştirilmeye çalışılan ülke incelemelerinde, genel hatlarıyla, politikaların hayata geçirilmesinde devletin yönetim yapıları etkili olmakla birlikte, çocuğa yönelik politikaların hayata geçirilmesinde merkezi ve yerel yönetimler arasında yetki ve sorumlulukların paylaşımı tespit edilmektedir (bkz. Tablo 1). Fakat son y1llarda ülkelerde gerçekleştirilen yeni düzenlemeler yerel yönetimleri ve özellikle belediyeleri, çocuk politikalarında öne çıkarmaktadır. Bu bağlamda İskandinav ülkelerinde Barnahus, merkezi yönetimin bir uzantısı olarak, çok disiplinli iş birliği 
yapısıyla konumlanmaktadır. Diğer taraftan yine merkezi yönetimin bir uzantısı olarak benzer bir işlevi gören birimler (Confidential Doctor Centres/Office) öne çıkmaktadır. Bunların dışında belediyeler bünyesinde oluşturulan komisyonlar, çocuk koruma konusunda faaliyet göstermektedir. Çocuk koruma konusu 1980'ler gündeme gelmeye başlamış, BM Çocuk Hakları Sözleşmesi'nin kabulünden sonra 1992 yılında ayrı bir düzenlemeye gidilmiştir (Akt. Samsonsen, 2016). Çocuk koruma konusunda yerel düzeyde belediyelere de kendi uygulamalarını yapma yetkisi verilmiştir. Bu nedenle bazı Batılı ülkelerde uygulanan ulusal bir çocuk koruma modelinin bulunmadığı ifade edilmektedir. Sunulan esneklik kapsamında belediyeler tarafından çeşitli risk değerlendirme modelleri geliştirilmiştir. Yerel oluşturulan çocuk koruma ofisleri, çocuklarla ilgili endişelerin araştırılmasına yönelik en iyi yöntemlerin geliştirilmesi için firsatlar sunmaktadır. Fakat yerel düzeyde gerçekleştirilen bu çabaların yeterli olmadığı, ulusal düzeyde kabul edilmiş kuralların olması gerekliliğinin de altı çizilmektedir (Akt. Samsonsen, 2016). Diğer taraftan yerel yönetim birimlerinin ve özellikle belediyelerin, eğitim, genel refah ve sosyal hizmetler bağlamında çocuğa yönelik politikaların önem kazandığı anlaşılmaktadır.

Tablo 1: Farkı Ülkelerin Yerel Düzeyde Çocuğa Yönelik Örgütlenme ve Politikaları

\begin{tabular}{|l|l|}
\hline Ülkeler & Yerel Yönetimler Düzeyinde Çocuğa Yönelik Örgütlenme ve Politikaları \\
\hline Norveç & $\begin{array}{l}\text { Merkezi ve yerel yönetimin yetki ve sorumluluğunda gerçekleşmekte } \\
\text { Yerelde çocuk refahı ve eğitim faaliyetleri öne çıkmakta }\end{array}$ \\
\hline İsveç & $\begin{array}{l}\text { Aile odaklı sosyal hizmetler bağlamında çocuklara odaklanılmakta } \\
\text { Çocuk izleme merkezleri (Bamahus) bulunmakta }\end{array}$ \\
\hline Hollanda & $\begin{array}{l}\text { Sosyal hizmetler bağlamında ele alınmakta } \\
\text { Belediyeler öne çıkmakta } \\
\text { Hizmetler yerinde (ailede) ve ihtiyaca özel sunulmakta } \\
\text { Çocuk izleme merkezleri bulunmakta }\end{array}$ \\
\hline İzlanda & $\begin{array}{l}\text { Belediyelerde çocuk koruma komiteleri bulunmakta } \\
\text { Çocuk evleri yer almakta }\end{array}$ \\
\hline Belçika & $\begin{array}{l}\text { Sağlık sisteminin bir parçası olarak çocuk koruma benimsenmekte } \\
\text { Aracı birimler (arabulucu komiteler, danışmanlar gibi) önem kazanmakta }\end{array}$ \\
\hline Portekiz & $\begin{array}{l}\text { Belediyeler bünyesinde risk altındaki çocuklar ve gençler için koruma } \\
\text { komisyonları bulunmakta (çocuk istismarını ve ihmalini tespit etmek } \\
\text { raporlamak ve durdurmak amacıyla) }\end{array}$ \\
\hline
\end{tabular}

\section{Sonuç}

İnsan unsuru, bir devletin varlığının ve devamlılığının temel parçalarından biridir. Dolayısıyla çocuklar, birinci derece devletin üzerinde durması gereken tarafı oluşturmaktadır. Diğer taraftan ise somut olarak çocukların varlı̆̆ı kentsel alanda ortaya çıkmaktadır. Kentler, 
çocukların da somut olarak yaşam pratiklerinin gerçekleştiği birinci öncelikli alanlardır. Bu noktada kentsel alanda çocuklar bugünün özneleridir. Diğer bir ifadeyle devlet açısından çocuklar, soyut düzeyde, geleceğin bir teminatı olarak görülürken, kentsel yaşamda bugünün öznesi olmaktadır (Alpan, 2015). Bugünün mevcut durumunda ve geleceğe yönelik öngörülerde, kentsel alanın öncelikli olarak tercih edildiği ve tercih edilmeye devam edileceği anlaşılmaktadır. $\mathrm{Bu}$ durum kentsel yaşamın bir paydaşı olarak çocukları daha fazla öne çıkaracaktır. Diğer taraftan çocuğun içinde bulunduğu fiziksel ve sosyal yapı, sorunları ve ihtiyaçları farklılaştırmaktadır. Örneğin, bir yaşam alanında oyun alanları temel bir ihtiyaca karşılık gelirken, başka bir yaşam alanında çocuk istismarı temel sorun alanlarından birine karşılık gelebilmektedir. Burada öne çıkarılan yereldeki farklılıklar, yerel yönetimlerin çocuklara yönelik sundukları hizmetlerin önemini, çeşitliliğini, miktarını ve kalitesini daha da önemli hale getirmektedir (Ömürgönülşen, 2007). Bilhassa gelişmemiş ve gelişmekte olan ülkelerde (ekonomik, sosyal ve kültürel kaynaklarla), bu durum daha fazla önem kazanmaktadır.

Tüm bu ifade edilenler çerçevesinde yerel düzeyde çocuğa yönelik örgütlenme ve politikalarda şu hususların önem kazandığı kanaati oluşmaktadır:

- ÇİM'lerin sayısının ve niteliğinin artırılması,

- Okul öncesi döneme ait eksikleri gidermek adına belediyeler tarafından kreş ve gündüz bakımevi sayılarının artırılması,

- Yine okul öncesi döneme yönelik aile içine yansıyacak bicimde eğitim materyali desteğinin verilmesi,

- Genel ve politika odaklı çocuğun katılımını sağlayacak mekanizmaların (komisyon, meclis gibi) kurulması ve etkin biçimde işletilmesi,

- Belediye bünyesinde çocuğa yönelik alt bir örgütlenmeye gidilmesi,

- Çocuk dostu kent yaklaşımının yaygınlaştırılması,

- Belediyelerin çocuğa yönelik bir eylem planının bulunması,

- Geliştirilecek politikalara farklı araçlarla çocuk katılımının sağlanması,

- Mevzuatta belirtilen nüfus eşiğini aşan kentlerin çocuklara yönelik konuk evlerini kurması,

- Üniversite çocuk araştırma ve uygulama merkezleriyle etkin iş birliklerinin gerçekleştirilmesi,

- Büyükşehirlerde ortaya çıkan çocuğa yönelik STK deneyimlerinin çeşitli yöntemlerle diğer kentlere de yansitilmasi. 


\section{Kaynakça}

Akarçay, P. (2017). Finlandiya, Danimarka ve Norveç’te Yerel Yönetimler. Akademik Sosyal Araştırmalar Dergisi, 5 (46), 352-372.

Aka, V. ve Güngör, F. (2019). Türkiye’de Çocuklara Yönelik Yerel Yönetim Politika ve Uygulamaları. Astana Yayınları (Ed.), Kamu Yönetimi ve Çocuk (s. 25-60). Ankara.

Akyüz, E. (2010). Çocuk Hukuku. Ankara: Pegem Akademi.

Almeida, M. A. (2018). Fighting Depopulation in Portugal: Local and Central Government Policies in Times of Crisis. Portuguese Journal of Social Science, 17 (3), 289-308.

Alpan, A. (2015). Mekân Sahipliği için Mekânı Çocuklarla Birlikte Üretmek: Eskişehir Odunpazarı için Bir Model Önerisi. İdeal Kent, 17, 202-251.

Bağ, Ö. Ve Alşen, S. (2016). Çocuğun Cinsel İstismarının Değerlendirilmesinde Yeni Model: Çocuk İzlem Merkezleri. İmir Dr. Behçet Uz Çocuk Hastanesi Dergisi, 6(1),9-14.

Baat, M. de, Linden, P. van der, Kooijman, K. ve Vink, C. (2011). CombatingChild Abuseand Neglect in the Netherlands, Netherlands Youth Institute, https://www.nji.nl/nl/Download-NJi/PublicatieNJi/(301995)-Daphne_report_Netherlands.pdf, 25. 08. 2019.

Berg, T. (2012). Combating Child Abuse and Neglect in Germany, Hungary, Portugal, Swedenand The Netherlands, https://www.youthpolicy.org/library/documents/combating-child-abuse-andneglect-in-germany-hungary-portugal-sweden-and-the-netherlands/, 27. 08. 2019.

Bilgener, S. Ç. ve Çalışkan, D. (2018). Çocuğu İstismardan Korumada Yeni Bir Yaklaşım: Çocuk İzlem Merkezleri, Pegem Akademi (Ed.), Prof. Dr. Emine Akyüz'e Armağan Akademisyenlikte 50. Y1l (119-127). Ankara.

Broz, Z. ve Wienen, J. (2017). Local Democracy in Iceland, https://rm.coe.int/16806fc29b, 26. 08. 2019.

Caluwaerts, L. (2010). Youth Policy in the Flemish Community, http://www.euromet.in/Child_YP_Belgium_en.pdf, Erişim tarihi: 27. 08. 2019.

Crompton, A. (2017). Local Government in Belgium: Decentralisation in Progress, https://www.lgiu.org.uk/wp-content/uploads/2017/08/Local-Government-in-Belgiumdecentralisation-in-progress.pdf, 27. 08. 2019.

Çakırer-Özservet, Y. (2018). Kent Havası Çocuğu Özgür Kılar mı?,Astana Yayınları (Ed.), Çocuk Üzerine Araştırmalar (87-109). Ankara.

Çakırer-Özservet, Y. (2016). Çocuklar İçin Katılımcı Yerel Yönetimler, Nobel Yayınları (Ed.), Çocuk Katılımı (91-128). Ankara.

Çocuk Dostu Şehirler, http://www.unicef.org.tr/files/bilgimerkezi/doc/CFC\%20Catalogue-TR.pdf, 30. 08. 2019.

Darwish, L., vanGaal, T. ve Nuyens, N. (2012). Being Young in the Netherlands, https://www.nji.nl/nl/Download-NJi/Publicatie-

NJi/Being_Young_in_the_Netherlands_2012.pdf, 25. 08. 2019.

Dede, D. (2011). Çok Düzeyli Yönetişim Olgusunun kent Konseyleri Bağlamında İncelenmesi: Helsinki, Stockholm, Bergen, Barselona Kent Konseyleri. Yayınlanmamış Yüksek Lisans Tezi, İstanbul Üniversitesi, SBE, İstanbul. 
Definition of Youth, https://www.youthpolicy.org/factsheets/country/belgium/, 28. 08. 2019

Desair, K. ve Adriaenssens, P. (2011). Policy Toward Child Abuse and Neglect in Belgium: Shared Responsibility, Differentiated Response, İçinde Child Protection Systems: International Trendsand Orientations, Edt. Neil Gilbert, Nigel Parton Ve Marit Skivenes, Oxford University Press, New York, ss. 204-222.

Emery, M. (1958). Provisions for the Protection of Children in Belgium and Sweden, Bulletin, June.

End Of Childhood Report (2018). TheMany Faces of Exclusion, https://campaigns.savethechildren.net/sites/campaigns.savethechildren.net/files/report/EndofChil dhood_Report_2018_ENGLISH.pdf, 24.08.2019.

Erginli, B. E. (2018). İstanbul İlçe Belediyelerinde Çocuğa ve Aileye Yönelik Hizmetler, TESEV Yayınları.

ESN (2014).I nvesting in Children's Services Improving outcomes, https://www.esneu.org/sites/default/files/publications/ESN_Investing_in_Children\%27s_Services\%2C_Improvin g_Outcomes.pdf, 26. 08. 2019.

European Commission (2015). Evaluation of Legislation, Policy and Practice on Child Participation in the European Union (EU), https://publications.europa.eu/en/publication-detail//publication/f425176f-cc2c-46bd-8a3a-65d958fff780, 28. 08. 2019.

Freymond, N. (2007). Using Intermediary Structures to Support Families: An International Comparison of Practice in Child Protection, içinde Moving Toward Positive Systems of Child and Family Welfare, Edt. Gary Cameron, NickCoady ve Gerald R. Adams, Wilfrid Laurier University Press, Kanada, ss. 161-185.

Güngör, S. (t.y.). Bakıma Muhtaç Çocuklar: Türkiye Ve Norveç Kurumsal Yapılarının Karşılaştırılması, Türk İdare Dergisi, http://www.tid.gov.tr/Makaleler/225\%20$\% 20241 \% 20$ servet\%20g\%C3\%BCng\%C3\%B6r.doc, 24. 08. 2019.

Government Agency for Child Protection, http://www.bvs.is/english/, 27. 08. 2019

Hilverdink, P., Daamen, W. ve Vink, C. (2015). Children and Youth Support and Care in the Netherlands, http://www.youthpolicy.nl/en/Download-NJi/Publicatie-NJi/Children-and-youth-support-andcare-in-The-Netherlands.pdf, 26. 08. 2019.

Humanium.org, Children in the World, https://www.humanium.org/en/children-world/, 26. 08. 2019.

Johansson, S., Stefansen, K., Bakketeig, E. ve Kaldal, A. (2017). Implementing the Nordic Barnahus Model: Characteristics and Local Adaptions, İçinde Collaborating Against Child Abuse Exploring the Nordic Barnahus Model, Edt. Susanna Johansson, Kari Stefansen, Elisiv Bakketeig ve Anna Kaldal, Palgrave Macmillan, ss. 1-34.

Johansson, S. (2017). Power Dynamics in Barnahus Collaboration, Palgrave Macmillan (Ed.), Collaborating Against Child Abuse Exploring the Nordic Barnahus Model (251-272).

Karatay, Z. (2019). Sivil Toplum Kuruluşlarının Çocuk Haklarının Korunması Ve Geliştirilmesinde Yeri: Çocuk Vakfı Örneği, Yayınlanmamış Yüksek Lisans Tezi, Giresun Üniversitesi, SBE, Giresun.

Kargın, N. (2013). Hollanda Yönetsel Düzeninde Yerel Yönetimler, Seçkin Yayıncılık (Ed.), Dünya'da Yerel Yönetimler (283-308). Ankara. 
Kent95 (2018). Kent95 Başlangıç Kiti Harekete Geçiren Fikirler, https://bernardvanleer.org/tr/publications-reports/an-urban95-starter-kit-ideas-for-action/, 29. 12. 2019.

Kent95, http://harita.kent95.org/, 01. 06. 2020

Key figures for the population, https://www.ssb.no/en/befolkning/nokkeltall/population, 26. 08. 2019.

Kidsrights Index, https://www.kidsrightsindex.org/Methodology/Reports-and-Publications1, 26. 08. 2019

Kojan, B. H. (2011). Norwegian Child Welfare Services: A Successful Program for Protecting and Supporting Vulnerable Children and Parents? Australian Social Work, 64 (4), 443-458.

Langford, M. ve Kirkebo, T. (2019). Children's Rights' Indexes: Measuring Norway's Performance, Children's Rights in Norway: An Implementation Paradox? (42-106), Universitetsforlaget.

Lopez, M. L., Bouma, H., Knorth, E. J. ve Grietens, H. (2019). The Dutch Child Protection System: Historical Overview and Recent Transformations, Springer (Ed.), National Systems of Child Protection Understanding the International Variability and Context for Developing Policy and Practice (173-192).

Magalhaes, M. J. ve Sottomayor, C. (2015).Working Paper on Intervention Against Child Abuseand Neglect in Portugal, https://www.londonmet.ac.uk/media/london-metropolitan-university/londonmet-documents/faculties/faculty-of-social-sciences-and-humanities/research/child-and-womanabuse-studies-unit/ceinav/CAN-working-paper_PT-final_BG.pdf, 28. 08. 2019.

Mamur Işıkcı, Y. (2019). Kamu Yönetimi ve Çocuk İlişkisi: Çocuk Hakları Bağlamında Bir Değerlendirme.Astana Yayınları (Ed.), Kamu Yönetimi ve Çocuk (1-24), Ankara.

Meys, A. (2010). Youth Policy in the German Speaking Community, https://rm.coe.int/16807023f1, 27. 08. 2019.

Netherland Youth Institü (2019). Evaluation of the Youth Act, http://www.youthpolicy.nl/en/Publications/Verzamelmap-Engelse-publicaties/Evaluation-of-theYouth-Act, 26. 08. 2019.

Nordfeldt, M. ve Larsson, O. S. (2011). Localwelfare in Sweden: Housing, Employment and Child Care, WILCO Publication, http://www.wilcoproject.eu/wordpress/wpcontent/uploads/WILCO_WP2_Report_03_SW1.pdf, 28. 08. 2019.

Norwegian Ministry of Local Government and Modernisation (2014). Local Government in Norway, http://www.mddsz.gov.si/fileadmin/mddsz.gov.si/pageuploads/dokumenti_pdf/enake_moznosti/ NFMStudijski2LokalnoUpravljanje.pdf, 24. 08. 2019.

Nososco (2017). Social Protection in the Nordic Countries: Scope, Expenditure and Financing, http://norden.diva-portal.org/smash/get/diva2:1148493/FULLTEXT02.pdf, 28. 08. 2019.

Ömürgönülşen, U. (2007). Türkiye’de Belediyelerin Çocuklara Yönelik Hizmetleri, İmge Kitabevi (Ed.), Yerellik ve Politika: Küreselleşme Sürecinde Yerel Demokrasi, Ruşen Keleş'e Armağan (s.117121). Ankara.

Pereira, A. (1991). The System of Local Government in Portugal, Macmillan (Ed.) Local Government in Europe (134-145). 
Pettersen, B. ve Monsen, N. (?). Norwegian Municipalities Bringing Social Services Back Into Public Hands, https://www.tni.org/files/publicationdownloads/chapter_4_reclaiming_public_services.pdf, 24. 08. 2019.

Price-Robertson, R., Bromfield, L. ve Lamont, A. (2014). International Approaches To Child Protection, https://aifs.gov.au/cfca/sites/default/files/publication-documents/cfca-paper23.pdf, 25. 08. 2019.

Pudar, G., Suurpää, L., Williamson, H. ve Zentner, M. (2013). Youthpolicy in Belgium, https://rm.coe.int/16807023f1, 27. 08. 2019.

Regeringskanliet-Finansdepartementet (2005). Local Government in Sweden - Organisation, Activities and Finance, https://www.vannas.se/default.aspx?di=2056, 28. 08. 2019.

Sanders, R. (2018). The Management of Child Protection Services: Context and Change, Routledge.

Samsonsen, V. (2016). Assessment in Childprotection; A Comparative Study Norway -England, University of Stavanger, Phd Thesis, Norveç, https://uis.brage.unit.no/uisxmlui/handle/11250/2373778? show=full, 24. 08. 2019.

SavetheChildren (2019). Changing Lives in Our Lifetime, Global Childhood Report 2019, https://resourcecentre.savethechildren.net/node/15264/pdf/ch1338551_0.pdf, 24. 12. 2019.

Silva, C. N. (2017). Political and Administrative Decentralization in Portugal: Four Decades of Democratic Local Government, Springer (Ed.), Local Government and Urban Governance in Europe (9-32).

Skivenes, M. (2011). Norway: Toward A Child-Centric Perspective, Oxford University Press (Ed.), Child Protection Systems: International Trendsand Orientations (154-179), New York.

Sverrisson, S. ve Hannesson, M. K. (2014). Local Governments in Iceland, https://www.samband.is/media/enska/SIS-enska.pdf, 26. 08. 2019.

Şehir Hepimizin: "Kente 95 cm'den Bakmak", https://www.youtube.com/watch?list=PL3ilA2pmbJRNyTQki0sdEnX4YVj6DDhNa\&v=B6cQC liimyo, 29. 12. 2019

TUIK (2018). İstatistiklerle Çocuk, https://biruni.tuik.gov.tr/yayin/views/visitorPages/index.zul, 31. 12. 2019.

Trthaber.com, Sayılarla dünyada Çocuk, https://www.trthaber.com/haber/yasam/sayilarla-dunyada-cocuk413850.html, 26. 08. 2019.

Uludağ, G. ve Mamur Işı1kcı, Y. (2019). Çocuk Haklarının Korunması ve Gelişmesinde Üniversitelerin Rolü, Astana Yayınları (Ed.), Kamu Yönetimi ve Çocuk (ss. 149-178), Ankara.

UNICEF (2017). Dijital Bir Çocuklar, http://www.unicef.org.tr/files/bilgimerkezi/doc/SOWC_2017_SUM_TR.pdf, Erişi̧m tarihi: 25. 12. 2019.

UNICEF (2019). The State of The World's Children, https://www.unicef.org/reports/state-of-worldschildren-2019, 25. 12. 2019.

UNPAN (2006). Kingdom of Norway Public Administration Country Profile, http://unpan1.un.org/intradoc/groups/public/documents/un/unpan023320.pdf, 24. 08. 2019.

Ürkmez, G. K. (2013). Belçika'da Yerel Yönetimler, Seçkin Yayıncıllk (Ed.), Dünya'da Yerel Yönetimler (143-162), Ankara. 
Vermeulen, W. (2015). Decentralization of Social Policy in the Netherlands, https://www.cpb.nl/sites/default/files/publicaties/download/cpb-background-documentdecentralization-social-policy-netherlands.pdf, 26. 08. 2019.

VNG (The Association of Netherlands Municipalities) (2018). Local Government in the Netherlands, https://www.publieksdiensten.nl/wp-content/uploads/2018/04/DENMARK-4-LocalGovernment-in-the-Netherlands.pdfi, 25. 08. 2019.

Wikipedia-İzlanda, https://tr.wikipedia.org/wiki/İzlanda\#Siyaset_ve_yönetim, 27. 08. 2019.

Wikipedia-Portekiz, https://tr.wikipedia.org/wiki/Portekiz, 28. 08. 2019.

Wikipedia-, İsveç, https://tr.wikipedia.org/wiki/\%C4\%B0sve\%C3\%A7\#\%C4\%B0ller_ve_belediyeler, 29. 08. 2019.

5393 Sayılı Belediye Kanunu

5216 Sayılı Büyükşehir Belediye Kanunu 